\title{
Patients' satisfaction survey on healthcare services among non- communicable disease patients at a tertiary care hospital in Puducherry
} Anandaraj Rajagopal ${ }^{1}$, Lalithambigai Chellamuthu ${ }^{2}$, Premnath Dhasaram ${ }^{3}$, Kavita Vasudevan ${ }^{4}$, Prakash Mathiyalagen ${ }^{5}$

${ }^{1}$ Assistant Professor, Department of Community Medicine, Indira Gandhi Medical College \& Research Institute, Puducherry; ${ }^{2}$ Senior Resident, Department of Community Medicine, Indira Gandhi Medical College \& Research Institute, Puducherry; ${ }^{3}$ Post Graduate, Department of Community Medicine, Indira Gandhi Medical College \& Research Institute, Puducherry; ${ }^{4}$ Professor \& Head, Department of Community Medicine, Indira Gandhi Medical College \& Research Institute, Puducherry; ${ }^{5}$ Assistant Professor, Department of Community Medicine, Indira Gandhi Medical College \& Research Institute, Puducherry

\begin{tabular}{|c|c|c|c|c|c|c|c|c|}
\hline Abstract & Introduction & Methodology & $\underline{\text { Results }}$ & Conclusion & $\underline{\text { References }}$ & Citation & \multicolumn{2}{|c|}{ Tables / Figures } \\
\hline \multicolumn{9}{|c|}{ Corresponding Autho } \\
\hline \multicolumn{8}{|c|}{$\begin{array}{l}\text { Dr. Lalithambigai Chellamuthu, Senior Resident, Department of Community Medicine, Mahatma } \\
\text { Gandhi Medical College and Research Institute, Pondicherry -Cuddalore Rd, ECR, Pillayarkuppam, } \\
\text { Puducherry } 607402 \\
\text { E Mail ID: lalli.muthu@gmail.com }\end{array}$} & 回都回 \\
\hline
\end{tabular}

\section{Citation}

Rajagopal A, Chellamuthu L, Dhasaram P, Vasudevan K, Mathiyalagen P. Patients' satisfaction survey on healthcare services among non-communicable disease patients at a tertiary care hospital in Puducherry. Indian J Comm Health. 2021;33(1):182-188. https://doi.org/10.47203/IJCH.2021.v33i01.025

Source of Funding: Nil Conflict of Interest: None declared

\section{Article Cycle}

Received: 16/11/2020; Revision: 15/01/20221; Accepted: 19/02/2021; Published: 31/03/2021 This work is licensed under a Creative Commons Attribution 4.0 International License.

\section{Abstract}

Background: Patient satisfaction is a scale to assess the services offered by the healthcare system. Patient's feedback is necessary to identify problems that need to be resolved in improving health services. Aim \& Objective: Keeping this in view, the present study is an initiative to estimate the patient's satisfaction in service provision among NCD patients at a tertiary care hospital of Puducherry. Settings and Design: A Facility-based descriptive cross-sectional study was conducted among NCD patients attending General medicine OPD of a tertiary care hospital of Puducherry between April-June 2019. Methods and Material: Assuming 50\% satisfaction level among study participants and $5 \%$ non-response rate, the sample size was estimated as 404 . The NCD register maintained at the General medicine OPD was considered as the sampling frame \& systematic random sampling was applied, so that every 5th patient satisfying the inclusion criteria will be included. A standardized patient satisfaction questionnaire with 31-items (4 domains) which is validated for Indian setting (Cronbach's alpha 0.96) was used. Statistical analysis used: Data capture was done using Epicollect-5 android application and analysed using SPSS version 16.0. Results: Among the 404 NCD patients, the mean age was $56 \pm 11.8$ (SD) years and $60.6 \%$ were females. One in four patients felt poor in reception, doctor-patient relationship and dispensary services. The overall satisfaction of study subjects categorized as good, satisfactory, poor was $6 \%, 86 \%$ and $8 \%$ respectively. Conclusions: Majority of the study participants were satisfied with the service provision of the health facility. Still, there is a scope for improvement in dispensary, doctor-patient relationship and registration services.

\section{Keywords}

Patient`s Satisfaction; Service Provision; NCD patients 


\section{Introduction}

Patient satisfaction is a scale to assess the services offered by healthcare system. It depends on quality of clinical services provided, availability of medicine, behaviour of healthcare providers, cost of services, hospital infrastructure, physical comfort, and emotional support.(1) Patients' feedback is imperative to identify problems that need to be resolved in improving the health services. Though, this is not carried out systematically to improve health services, this type of feedback triggers a real interest that can lead to a change in healthcare provider's culture and in their perception of patients.(2) Patient's satisfaction seems to be decreasing and communication gap between doctors and patients are increasing. It is one of the main reasons of recently reported upsurge in medical violence incidents. (3) Patients' dissatisfaction can cause shift of patients to either costly private hospitals or cheap treatment by quacks resulting in poor quality of health care. Thus, the public health care system must seek to reorganize itself to ensure the effective delivery of quality services to all patients.(4)

There seems to be an epidemiological shift from communicable to non-communicable diseases (NCDs) globally as well as in India. The present-day approach to healthcare demands to embrace the attention of both patients and public in developing healthcare services and equity of access, but this is not easy to achieve, as it requires time, commitment and political support. Therefore, improvements in selected areas of health care delivery can be done through quality assurance and outcome assessment.(4) Patients' satisfaction can be used as a proxy measure of quality of health care services.(5)

There are published research articles available on satisfaction level for general patients in India and also in Puducherry but there is a dearth of knowledge on specific group of patients who utilize the services offered at public health sector on a regular basis rather than being a one-time visitor of a heath facility and this would give a true estimate of the patients' satisfaction.

\section{Aims \& Objectives}

To estimate the patients' satisfaction in service provision among NCD patients at a tertiary care hospital in Puducherry

\section{Material \& Methods}

A descriptive cross-sectional study was conducted among 404 patients attending non-communicable disease (NCD) clinic under the General medicine outpatient department of a tertiary care hospital in Puducherry over a period of three months (May-July 2019). The NCD patients attending the clinic include patients with cardiovascular diseases, diabetes, hypertension, Dyslipidemia, Bronchial asthma, Epilepsy. The purpose of the study was clearly explained to the participants and written informed consent was obtained from them before the start of the study.

Consenting patients of either gender registered in the NCD clinic (functions separately but located in the General medicine OPD) and on medications for a minimum period of one month in the study setting were enrolled for the study. Terminally ill patients or those who were not comprehensive enough for data collection were excluded. Assuming $50 \%$ satisfaction levels among the study participants with $5 \%$ absolute precision, 95\% confidence limits and non-response rate of $5 \%$, the sample size was estimated to be 404 . The NCD register maintained at the General medicine OPD was considered as the sampling frame \& systematic random sampling was applied so that every fifth patient registered in the NCD register fulfilling the eligibility criteria was included as the study participants. Ethical approval (No.216/ IEC-25/ IGMC\&RI/ F-7/ 2019) and administrative permission were obtained prior to the start of the study.

The study tool comprised of two parts, with part one pertaining to demographic details and treatment seeking behaviour of the study subjects, while part two contained a standardized patient satisfaction questionnaire with 31-items divided into four domains. This questionnaire has been validated for Indian setting (Cronbach's alpha 0.96). (6) The four domains include General (4 items), Reception/registration (10 items), Doctor-Patient relationship (9 items), Pharmacy ( 7 items) and overall satisfaction. Each question was scored in a scale of 1 to 5 where $1,2,3,4 \& 5$ corresponds to strongly disagree, disagree, neutral, agree and strongly agree respectively.

Data was captured in a smartphone using Epi-collect 5 android application and analysis was performed in SPSS software version 16.0. Patient responses to items under each domain were summed and categorized into good, satisfactory and poor based 
on 75th \& 25th percentiles in the total responses for each domain. Descriptive statistics was computed using frequency and percentage for categorical data and median for continuous data.

\section{Results}

The study conducted among 404 NCD patients attending General medicine OPD showed that the mean \pm SD age of the participants was $56.2 \pm 11.8$ years. Males comprised $39.4 \%$ of the respondents while $60.6 \%$ were females. About $72.3 \%$ respondents were literates and $69.6 \%$ were employed. The most common non-communicable disease for which treatment was sought by the study participants was diabetes mellitus (76.7\%) followed by hypertension (60.1\%). [Table 1]

All respondents expressed high scale of satisfaction for accessibility of the OPD and its location (82.9\%) and $75.7 \%$ for the parking area facility; however, participants rated lower satisfaction judgement with the signage system (36.4\%) and with cafeteria facility it was observed to be only $50.5 \%$. [Table 2]

In respondents' satisfaction concerning certain attributes like information received and courteousness of staff at the registration counter was documented to be $78 \%$ and $75.7 \%$ respectively. The study participants were inconsiderable with the queue system and registration time at the registration counter, which amounted to $65.1 \%$ and $61.6 \%$ respectively. Almost all respondents reflected a good satisfaction judgement against certain structural attributes like seating facility $(77 \%)$ and toilet facilities (73.8\%). One extenuating feature was the high level of satisfaction of respondents $82.2 \%$ with respect to drinking water availability at the registration. [Table 2]

The subjects showed a lower satisfaction level, $53.5 \%$ and $35.6 \%$ with the number of doctors available and waiting time for consultation respectively. Whereas the patients were well satisfied with the consultation room environment (74.3\%) and consultation time with the doctor (74.5\%). The most reassuring is the high level of satisfaction of respondents, $79.5 \%$ and $77.5 \%$ against the care attributes of communication about the disease process and sense of concern shown by the doctors to the patients during consultation. [Table 2] The patients had a varied level of satisfaction with respect to dispensary domain. The respondents expressed high satisfaction judgement for the location of the dispensary counters (84.2\%) while the respondents were not so happy about the waiting time for collection of medicines (54.5\%). It was observed that the patients were not satisfied with availability of the drugs (45\%). The study revealed that the majority of respondents had been highly satisfied with courteousness of staff at the pharmacy counter and with the explanation given by pharmacists for dosages of prescribed medicines which accounted for $79.5 \%$ and $78.5 \%$ respectively. [Table 2]

A fair number of participants $77 \%$ and $72 \%$ had reflected satisfactory results pertaining to general domain and reception domain respectively. A moderate number of participants $65 \%$ and $60 \%$ had shown satisfactory results pertaining to doctorpatient relationship domain and dispensary domain respectively. Most of the respondents rated overall feeling about visit to hospital out-patient department services as satisfactory (86\%). [Figure 1]

\section{Discussion}

The present patient satisfaction study had been conducted among 404 NCD patients attending the General medicine OPD regularly. The mean \pm SD age in years of the participants was found to be $56.2 \pm$ 11.8 years in this study whereas the mean age of the patients was 38.04 years in another study conducted among general OPD patients in a tertiary care hospital at Puducherry.(7) Another study conducted among OPD patients at a primary health center in Puducherry documented that the mean age of patients to be 44.3 years.(1) The difference with mean age in the present study when compared to other studies from same geographical region could be because of the fact that the present study included only the non-communicable disease (NCD) patients and did not take into account the general OPD patients like other studies.

In the present study, females were more compared to males which were similar to a study from Karaikal, where the total study population comprised $61.6 \%$ females (8) while in other studies majority of the study participants were males. $(7,9)$ About $27 \%$ of them had no formal education but another study from Puducherry showed that around three-fourth of the respondents were illiterate and below SSLC.(7) This difference in literacy could be attributed to the fact that the present study was from an urban setting where as the other study was conducted in rural areas. Less than two-third were only unemployed among the study participants. Similar finding was 
published by Rose A et al. (10) The most common non-communicable disease for which the treatment was sought by the study participants was diabetes mellitus followed by hypertension. This was similar to a study where nearly half of the participants interviewed were attendees of chronic disease clinic with the main presenting conditions as hypertension and diabetes. (8)

All respondents declared high degree of satisfaction for accessibility of the OPD and its location (82.9\%) which was consistent with the findings by Mohd $A$ et al and Arshad AS et al. $(6,10)$ Also the participants showed a good satisfaction level for the parking area facility while it was low in a study conducted by Mohd A et al.(6) Patients rated lower satisfaction judgement with the signage system and with cafeteria facility which was again parallel with findings by Mohd A et al.(4)

Pertaining to information received and courteousness of staff at the registration counter, the study participants had shown high satisfaction level which was same as that of the study where participants had expressed high satisfaction with the attitude and behaviour of health staff, explanation and guidance given to them. $(11,12)$ All respondents expressed a good satisfaction judgement against certain structural attributes like seating facility and toilet facilities. Also, there existed a high level of satisfaction of all respondents in respect to availability of drinking water at the registration. These findings were consistent with a study conducted by Sodani PR et al. (2) The high satisfaction level with the structural attributes could be because of the quality check and control by regular inspection by NABH (National Accreditation Board for Hospitals) in medical colleges and by following and maintaining IPHS (Indian Public Health Standards) at every hospital.

Respondents asserted a lower satisfaction level with the number of doctors available and waiting time for consultation. These findings were correlating with the findings from a study done by Quadri SS et al. (13) This could be substantiated by the fact that the study setting is a government tertiary care hospital. Hence, a large number of patients from the Puducherry and also from neighboring districts of Tamil Nadu are expected to be catered by the hospital which in turn has an impact on waiting time for consultation. There prevailed a high level of satisfaction of respondents, against the care attributes of communication about the disease process, sense of concern shown by the doctors to the patients during consultation and consultation time with the doctors which were similar to studies done by Singh S et al and Baruah M et al. $(14,15)$ The participants in the present study were not so happy about the waiting time for collection of medicines at the dispensary counters which was consistent with findings from similar studies. $(16,17,18)$ The long duration of waiting time for collection of medicines in the present study could be again substantiated because of the patient load to the hospital. Other reason could be the time spent on explanation about the dosage of drugs to each patient, peak timings where the patients load is more on certain days like Monday and Saturdays.

Majority of the present study subjects were highly satisfied with the courteousness of staff and explanation given to patients for dosages of prescribed medications and other necessary instructions which were similar to a study conducted at Jaipur, India.(2) Most of the respondents rated overall feeling about visit to hospital OPD services as satisfactory which was consistent with a study conducted by Mohd A et al.(6)

\section{Conclusion}

Overall, a majority of the study participants were oberved to have satisfactory levels with the services provided by the NCD clinic, with the satisfaction levels declining when the assessment from general domain to pharmacy domain.

A good number of participants had shown satisfactory results pertaining to general domain and reception domain. A moderate number of participants had shown satisfactory results pertaining to doctor-patient relationship domain and dispensary domain. Most of the respondents rated overall feeling about visit to hospital OPD services as satisfactory. Still, there is a scope for betterment in signage system of the hospital and cafeteria facility with a clinch on NABH and IPHS guidelines

\section{Recommendation}

The satisfaction level with waiting time for consultation was found to be less which could be addressed by adopting the "queuing theory" which would probably aid to reach optimal solution to proper channeling of the patients. Other measure could be increasing the appointment of physicians to cater the patient load and achieving the ideal doctorpatient ratio, 1:1000 as recommended by World Health Organization. Improvement of the dispensary 
concerning availability of drugs could be made possible by following proper inventory control methods like strict adherence to First-in-First-out policy.

\section{Limitation of the study}

The limitations could be that very few participants found the five-point scale difficult in understanding and the results of the present study cannot be generalized as it involved only one hospital. The strength of the present study could be utilization of a standardized questionnaire, validated for Indian setting with high reliability

\section{Relevance of the study}

In the field of public health, quality healthcare service is an important component and patient satisfaction is considered as an outcome measure for quality of healthcare. It acts as a yardstick to measure success of the service delivery system functional at hospitals. Current study provides the insight about the NCD patients' satisfaction in service provision at a tertiary care hospital. This would help the administrators to identify the key areas to focus in planning the effective strategies to improve the quality of health services in Government health sectors right from primary health care level to tertiary care level as NCD patients are catered at all tires of health care system in India.

\section{Authors Contribution}

All authors have contributed equally.

\section{Acknowledgement}

We would like to express our gratitude to Head of the Institute as well as Head of the Department of General Medicine for their approval for conduct of the study

\section{References}

1. A Raghunath E, Vijayalakshmi S, Sathagurunath PA. A study of outpatient satisfaction at primary health centers in Puducherry. Health agenda. 2013;1(4):118-21.

2. Sodani PR, Kumar RK, Srivastava J, Sharma L. Measuring patient satisfaction: a case study to improve quality of care at public health facilities. Indian J Community Med. 2010;35(1):52-6. doi: 10.4103/0970-0218.62554. PMID: 20606920; PMCID: PMC2888368.[PubMed].

3. Bhattacharya S, Singh A. Patient-centric approach through "Multi-Purpose Behavior Therapy (MPBT)" room for improving patient's satisfaction and decreasing work load in Hospitals: An analysis from available evidence. CHRISMED J Health Res. 2019;6(3):135-9.

4. Chattopadhyay A, Saha T, Karmakar P, Sengupta P, Boral K, Yasmin S. Patient satisfaction evaluation in CGHS
[Patients' satisfaction survey...] | Rajagopal A et al dispensaries in Kolkata, India. J Dent Med Sci. 2013; 6(4):139.

5. Garg N, Gupta SK, Mahesh R. Patient satisfaction survey at a tertiary care specialty hospital. Int J Res Foundation Hosp Healthc Adm. 2014;2(2):79-83.

6. Mohd A, Chakravarty A. Patient satisfaction with services of the outpatient department. Med J Armed Forces India. 2014;70(3):237-42. doi: 10.1016/j.mjafi.2013.06.010. Epub 2014 Jun 25. PMID: 25378776; PMCID: PMC4213903.[PubMed].

7. Ghose A, Adhsih VS. Patient satisfaction with medical services: Hospital-based study. Health Popul. 2011;34(4):232-42.

8. Dharmasivam S, Selvaraj R, Lakshminarayanan S, Kar SS, Kumar SG. Quality of medication services for morbidities in a rural health center in Puducherry, India. J Family Med Prim Care. 2017;6(3):538-542. doi: 10.4103/22494863.222022. PMID: 29417004; PMCID: PMC5787951.[PubMed].

9. Naik JR, Anand B, Bashir I. Healthcare Service Quality and word of mouth: Key drivers to achieve Patient Satisfaction. Pacific Business Review International. 2013;5(12):39-44.

10. Rose A, Shashidhara YN. Satisfaction on healthcare services among people living with non-communicable diseases. Manipal Journal of Nursing and Health Sciences. 2015;1(2):108-11.

11. Arshad S, Andrabi H, Hamid, Shamila, Masooda S. Measuring patients satisfaction: a cross sectional study to improve quality of care at a tertiary care hospital. East Afr J Public Health. 2012;9(1):26-8. PMID: 23120945.[PubMed].

12. Sudhan A, Khandekar R, Deveragonda S, Devi $S$, Jain BK, Sachan R, Singh V. Patient satisfaction regarding eye care services at tertiary hospital of central India. Oman J Ophthalmol. 2011;4(2):73-6. doi: 10.4103/0974620X.83657. PMID: 21897622; PMCID: PMC3160073.[PubMed].

13. Qadri SS, Pathak R, Singh M, Ahluwalia SK, Saini S, Garg PK. An assessment of patient's satisfaction with services obtained from a tertiary care hospital in rural Haryana. Int J Collaborative Res Internal Med Public Health. 2012;4(8):1524-37.

14. Singh $S$, Kaur $P$, Rochwani R. Patient satisfaction levels in a tertiary care medical college hospital in Punjab, North India. Int J Res Dev Health. 2013; 1:172-82.

15. Baruah M, Dawka K, Kataki AC. Patient satisfaction: a tool for quality control. Int J Community Med Public Health. 2017;3(5):1215-8.

16. Prasanna K, Bashith M, Sucharitha S. Consumer Satisfaction about Hospital Services: A Study from the Outpatient Department of a Private Medical College Hospital at Mangalore. Indian J Community Med. 2009;34(2):156-9. doi: 10.4103/0970-0218.51220. PMID: 19966965; PMCID: PMC2781126.[PubMed].

17. Joshi K, Sochaliya K, Purani S, Kartha G. Patient satisfaction about health care services: A cross sectional study of patients who visit the outpatient department of a civil hospital at Surendranagar, Gujarat. Int J Med Sci Public Health. 2013;2(3):659-64.

18. Rasheed N, Arya S, Acharya A. Client satisfaction and perceptions about quality of health care at a primary health centre of Delhi, India. Indian J. Community Health. 2012;24(3):237-42. 


\section{Tables}

TABLE 1 SOCIO-DEMOGRAPHIC CHARACTERISTICS OF STUDY POPULATION ( $\mathrm{N}=404$ )

\begin{tabular}{|l|c|}
\hline Age group & $n(\%)$ \\
\hline Less than 45 years & $82(20.3)$ \\
\hline $45-60$ years & $165(40.8)$ \\
\hline More than 60 years & $157(38.9)$ \\
\hline Gender & $159(39.4)$ \\
\hline Male & $245(60.6)$ \\
\hline Female & $292(72.3)$ \\
\hline Education & $112(27.7)$ \\
\hline Literate & \\
\hline No formal education & $123(69.6)$ \\
\hline Occupation & $281(30.4)$ \\
\hline Employed & $310(76.7)$ \\
\hline Unemployed & $243(60.1)$ \\
\hline Non-communicable diseases* & $36(8.9)$ \\
\hline Diabetes & $27(6.7)$ \\
\hline Hypertension & $59(14.6)$ \\
\hline Dyslipidaemia & \\
\hline Cardio-vascular disease & \\
\hline Others & \\
\hline
\end{tabular}

\section{TABLE 2 SATISFACTION LEVEL SCORE OF STUDY POPULATION IN VARIOUS DOMAINS (N=404)}

\begin{tabular}{|c|c|c|c|}
\hline Question & Median & SD & $\%$ \\
\hline \multicolumn{4}{|l|}{ General } \\
\hline Q1. Accessibility/location & 5.00 & 0.46 & 82.9 \\
\hline Q2. Signage system & 4.00 & 0.91 & 36.4 \\
\hline Q3. Parking facilities & 5.00 & 0.64 & 75.7 \\
\hline Q4. Cafeteria facility & 5.00 & 1.08 & 50.5 \\
\hline \multicolumn{4}{|l|}{ Reception/Registration } \\
\hline Q5. Information received & 5.00 & 0.65 & 78.0 \\
\hline Q6. Queue system & 5.00 & 0.66 & 65.1 \\
\hline Q7. Courteousness of staff & 5.00 & 0.73 & 75.7 \\
\hline Q8. Registration time & 5.00 & 1.14 & 61.6 \\
\hline Q9. Waiting area & 5.00 & 0.85 & 66.3 \\
\hline Q10. Seating facility & 5.00 & 0.61 & 77.0 \\
\hline Q11. Drinking water availability & 5.00 & 0.60 & 82.2 \\
\hline Q12. Toilets facility & 5.00 & 0.74 & 73.8 \\
\hline Q13. Magazines/TV etc & 1.00 & 0.87 & 88.1 \\
\hline Q14.Cleanliness & 4.00 & 0.85 & 41.3 \\
\hline \multicolumn{4}{|l|}{ Doctor-Patient Relationship } \\
\hline Q15.Number of doctors & 5.00 & 0.95 & 53.5 \\
\hline Q16. Waiting time & 3.00 & 1.01 & 29.2 \\
\hline Q17. Satisfaction level with waiting time & 3.00 & 0.92 & 35.6 \\
\hline Q18. Doctors' room environment & 5.00 & 0.66 & 74.3 \\
\hline Q19. Consultation time & 5.00 & 1.06 & 74.5 \\
\hline Q20. Satisfaction level with consultation time & 5.00 & 0.78 & 74.8 \\
\hline Q21. Explanation about sickness by doctor & 5.00 & 0.53 & 79.5 \\
\hline Q22. Sense of concern & 5.00 & 0.5 & 77.5 \\
\hline Q23. Dignity/privacy & 5.00 & 0.67 & 71.0 \\
\hline \multicolumn{4}{|l|}{ Dispensary } \\
\hline Q24. Location of dispensing counters & 5.00 & 0.46 & 84.2 \\
\hline
\end{tabular}




Q25. Waiting area
Q26. Queue system

Q27. Courteousness of staff 5.00

5.00

5.00

5.00

4.00

5.00

Q28. Waiting time

Q29. Availability of drugs

Q30. Explanation about medicines and dosages

3.00

0.60

76.0

0.64

79.5

Overall response

Q31. Overall feeling about visit to hospital

3.00

1.22

54.5

45.0

78.5

\section{Figures}

\section{FIGURE 1 SUMMATIVE SATISFACTION LEVEL OF STUDY POPULATION ( $N=404)$}

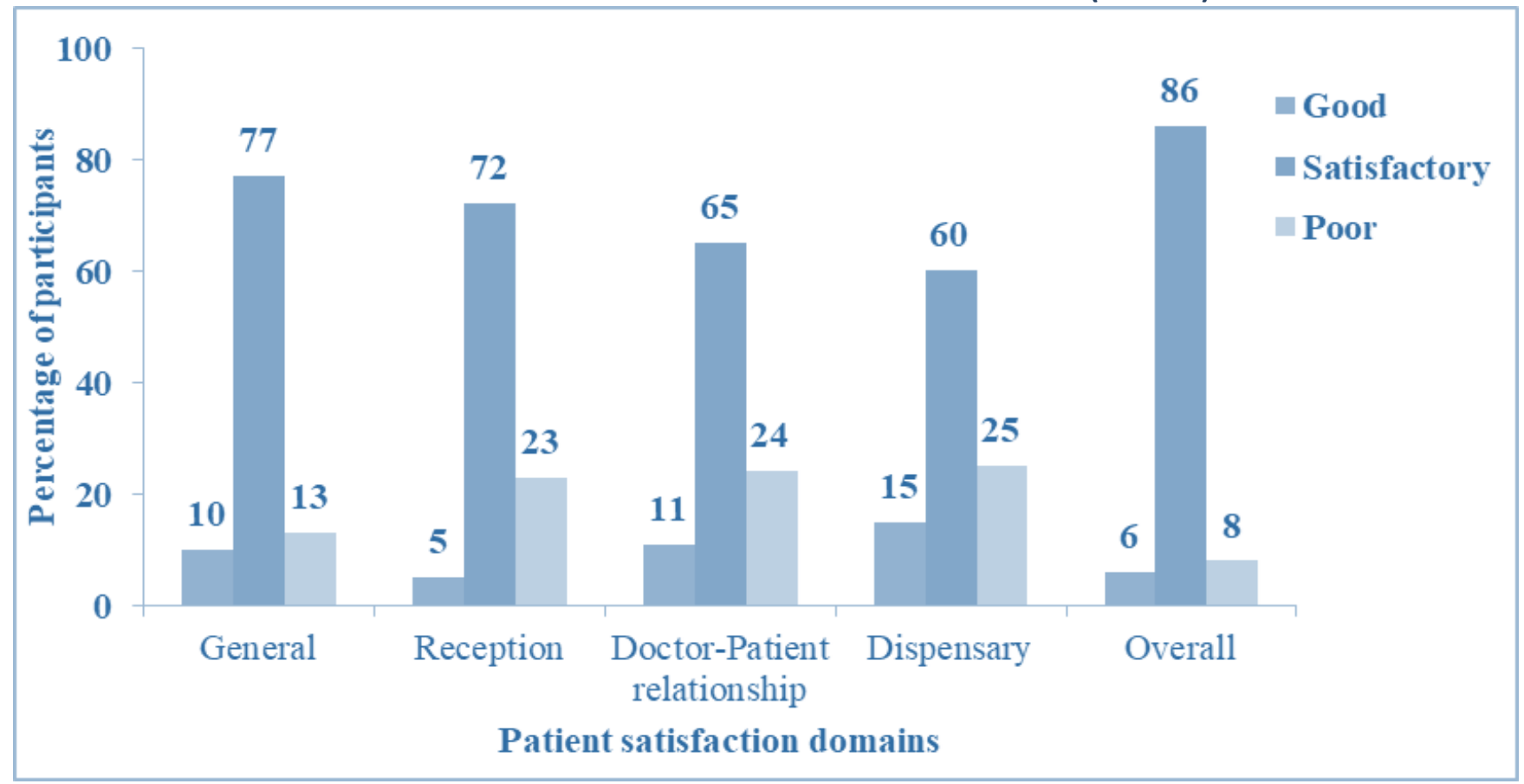

